\title{
OPTIMIZATION AND VALIDATION OF HPLC METHOD FOR THE ANALYSIS OF KETOTIFEN FUMARATE IN A PHARMACEUTICAL FORMULATION
}

\author{
M. H. Semreen
}

Faculty of Pharmacy, Al Isra University, Amman, Jordan, P.O. Box 22,33. P.O. 11622

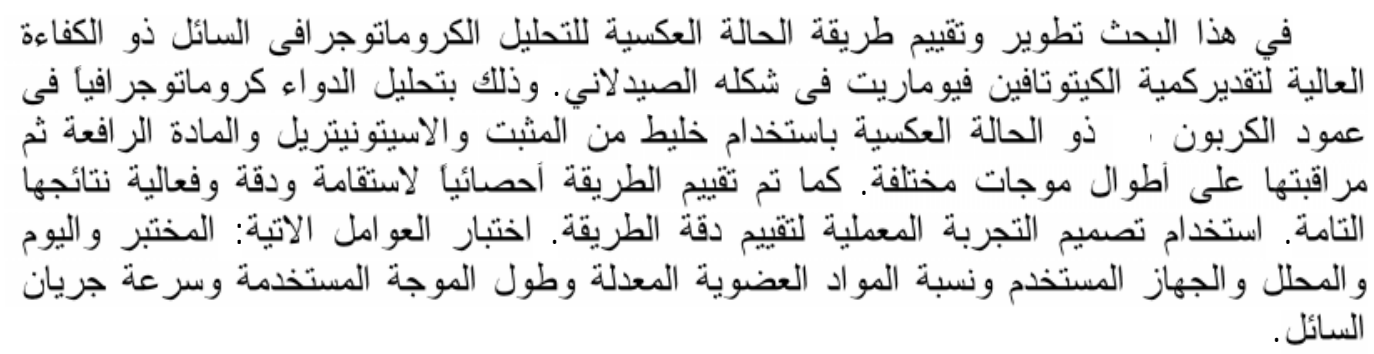

A reversed phase high-performance liquid chromatographic (HPLC) method was developed and validated for determination of ketotifen fumarate in a pharmaceutical formulation?

The drug was chromatographed on reversed-phase C18 column, using mixtures of phosphate buffer/acetonitrile. The eluents were monitored at different wavelengths. The method was validated statistically for its linearity, accuracy, robustness and precision. Experimental design was used during validation to evaluate method robustness and for the determination of intermediate precision. Factors examined for statistical approaches include; laboratory, day, analyst, instrument, percentage of organic modifier, wavelength and flow-rate. Due to its simplicity and accuracy, the method percentage may be used for routine quality control analysis.

\section{INTRODUCTION}

Ketotifen is a benzocycloheptathiophene of long-acting antihistaminic and antianaphylactic properties. The significant antihistaminic and anti-anaphylactic properties may be usefulness in asthma prophylaxis and in symptomatic improvement of allergic condition including rhinitis and conjunctivitis. Ketotifen has acquired these properties through its sustained inhibitory effect on the release of some local mediators such as histamine. However, the prophylactic activity of ketotifen may take several weeks to become fully established, and so, it can not abort the established attacks of asthma. ${ }^{1}$

Some HPLC methods have been reviewed for the determination of ketotifen fumarate in biological fluids ${ }^{2}$ based on UV detection.<smiles>CN1CCC(=C2c3ccccc3CC(=O)C3SC=CC23)CC1</smiles>

Chemical structure of Ketotifen Fumarate

This paper reports a rapid and HPLC method with UV detection for routine quality control of ketotifen fumarate in a pharmaceutical formulation. The method was 
validated by linearity, accuracy, precision and robustness. Experimental design was used during validation to evaluate method robustness and for the determination of intermediate precision.

\section{EXPERIMENTAL}

\section{Apparatus}

Different HPLC systems were used at the two laboratories involved in this study.

The specification are provided below.

LAB. A: The HPLC 1 apparatus was a Merck Hitachi chromatographic system pump (L-6200A) equipped with a suptumless injector (Rheodyne 7725). An UV detector (L-4000A) was used. Peak area integration were performed using a chromatographic data system (PE NELSON 1022 HPLC system manager program) a Hypersil reversed-phase $\mathrm{C}_{18}$ column $(25 \mathrm{~cm} \times 4.6 \mathrm{~mm}$ i.d., particle size $5 \mathrm{~m})$ was utilized.

LAB. B: The HPLC 2 apparatus was Waters chromatographic system pump (Waters 510 HPLC) equipped with a septumless injection (Rheodyne 7725). An UV detector (Waters 486 Tunable Absorbance Detector) was used. Peak area integration was performed using a chromatographic data system (Waters 746 Data Model). a Hypersil reversed-phase $\mathrm{C}_{18}$ column $(25 \mathrm{cmx} 4.6 \mathrm{~mm}$ i.d., particle size $5 \mathrm{~m}$ ) was used.

The experimental design was produced, and statistical analysis of the data was performed, by Nemrod software ${ }^{3}$ (LPRAI, Universite de Marseille III, France).

\section{Chemicals and Reagents}

Acetonitrile was purchased from Scharlau (Barcelona, Spain). Deionized water was in the mobile phase, distilled and filtered through a $0.45 \mathrm{~m}$ millipore filter (Sartorius, Germany) under vacuum before use.

Potassium dihydrogen phosphate (GGC DIAGNOSTICS, U.K) was analytical grade.

Ketotifen fumarate standard was supplied by The RAM Pharmaceutical Industries (Amman-Jordan).

\section{Preparation of standard / sample solutions}

The preparation of standard / sample solutions was by weighing $(60.23,70.47,80.8$, $90.6,100.17) \mathrm{mg}$ of ketotifen fumarate into 100 $\mathrm{ml}$ volumetric flask. The substances were dissolved and diluted to volume with the mobile phase stated above.

\section{Calibration curve}

Five solutions at five different concentrations were prepared by dissolving the amount of ketotifen fumarate in the mobile phase. The final concentrations of ketotifen fumarate were $0.6023,0.7047,0.808,0.906$, $1.017 \mathrm{mg} / \mathrm{ml} \mathrm{respectively.} \mathrm{Before} \mathrm{injecting}$ solutions, the column was equilibrated for at least $30 \mathrm{~min}$ with the mobile phase flowing through the system. Six determinations were carried out for each solution. Peak areas were recorded for all the solutions. The calibration graph was constructed by plotting the peak areas obtained at the optimum wavelength of detection versus the injected amounts.

\section{Chromatographic conditions}

The mobile phase was a mixture of $0.5 \mathrm{~g}$ potassium dihydrogen phosphate in $700 \mathrm{ml}$ water, $\mathrm{pH}=4.0$ and acetonitrile (70: $30, \mathrm{v} / \mathrm{v})$. The flow rate was $1.5 \mathrm{ml} / \mathrm{min}$. The UV detector wavelength was set at $298 \mathrm{~nm}$ and an attenuation of 1.0 a.u.f.s was used.

\section{RESULTS AND DISCUSSION}

A chromatogram of ketotifen fumarate is shown. The substance is well resolved with retention time of $2.438 \mathrm{~min}$, by using Potassium dihydrogen phosphate in $700 \mathrm{ml}$ water, $\mathrm{pH}=4.0$ and acetonitrile $(70: 30, \mathrm{v} / \mathrm{v})$ as mobile phase. The method was validated statistically for its linearity, accuracy, robustness, and Precision as will be discussed.

\section{Linearity}

The linearity of peak area response versus concentrations was studied from 0.6023 to $1.017 \mathrm{mg} / \mathrm{ml}$ for ketotifen fumarate. A linear response observed over the examined concentration range. As show from the slope 4874406, intercept -110717 , and the correlation coefficient 0.9995 .

\section{Recovery /Accuracy}

Accuracy was studied at three different concentrations, corresponding to $0.650,0.824$ and $1.002 \mathrm{mg} / \mathrm{ml}$. drug recovery data obtained were within the range $99.4-100.5 \%$ and RSD 
was $0.55 \%$ (Table 1), satisfying the acceptance criteria for the study.

Table 1: Accuracy/recovery for ketotifen fumarate

\begin{tabular}{||c|c|c||}
\hline $\begin{array}{c}\text { Conc. } \\
(\mathrm{mg} / \mathrm{ml})\end{array}$ & $\begin{array}{c}\text { Recovery } \\
(\%)\end{array}$ & $\begin{array}{c}\text { RSD } \\
(\%)\end{array}$ \\
\hline 0.650 & 100.5 & 0.62 \\
\hline 0.824 & 99.4 & 0.13 \\
\hline 1.002 & 99.9 & 0.25 \\
\hline Mean & 99.9 & 0.55 \\
\hline
\end{tabular}

$\mathrm{n}=4$

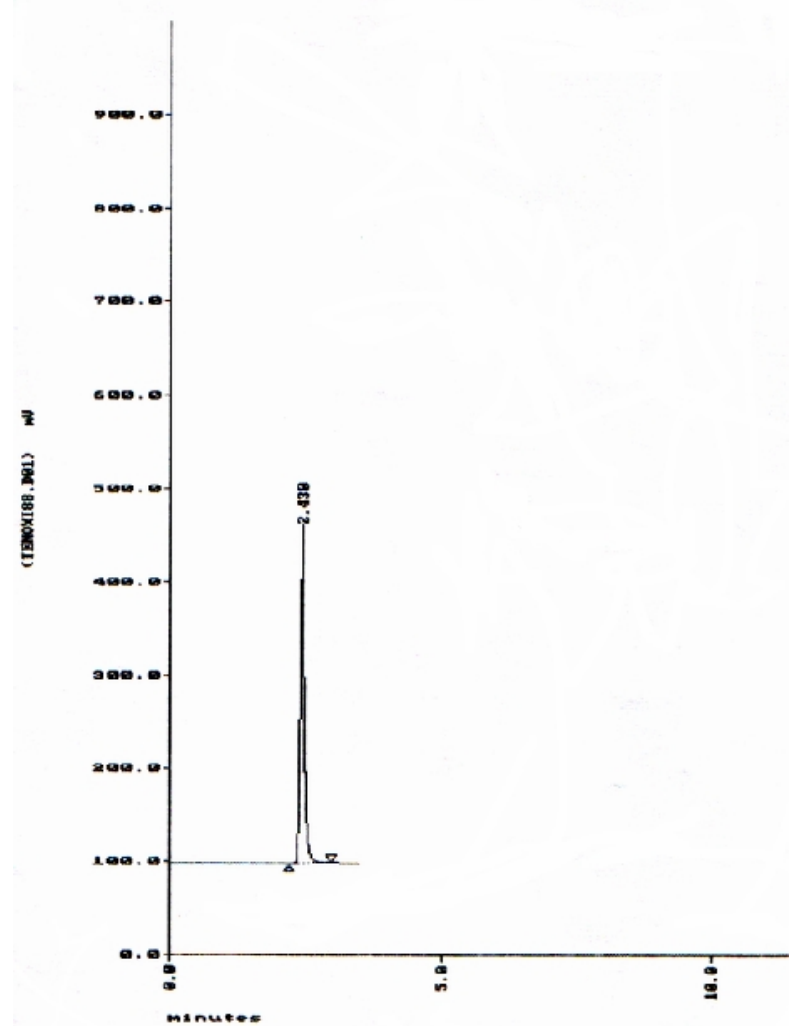

Chromatogram of a solution containing ketotifen fumarate (tr. $2.438 \mathrm{~min}$ ) at the concentration of $0.808 \mathrm{mg} / \mathrm{ml}$ at the optimized chromatographic conditions.

\section{Repeatability}

The system repeatability was assessed from twelve replicate injections of a sample solution of ketotifen fumarate at the analytical concentration of $0.8211 \mathrm{mg} / \mathrm{ml}$. The RSD for the active principle was found to be $0.52 \%$ and the R.S.D\% was found to be 0.52 .

\section{Robustness testing}

Robustness testing was performed in order to obtain information about those critical parameters affecting the response (peak area). The robustness of the method can be tested using experimental design in order to study the simultaneous variation of the factors.

As a result of data analysis, one is able to indicate which of the tested factors are not robust for the considered response. When factors that are not robust are detected one can decide to change the method or to control the factor in question more strictly. ${ }^{4-9}$

To carry out robustness testing with experimental design, it is necessary to select the factors and the levels at which to test them, followed by the selection of the suitable design, which depends on the postulated relationship. In general linear models are sufficient and advisable because of the small experimental domain and for the reduction in the number of experiment. For each controlled factor it is necessary to know its optimized value in order to define the interval within it can be controlled.

In the assessment of HPLC method for Ketotifen Fumarate all the studied factors during the optimization process (organic modifier percentage, $\boldsymbol{b}_{1} ; \mathrm{pH}, \boldsymbol{b}_{2} ; \lambda, \boldsymbol{b}_{3}$; flow rate, $\boldsymbol{b}_{4}$ ) were considered Table (2).

Table 2: Method settings and range investigated during robustness testing.

\begin{tabular}{|c|c|c|}
\hline Variable & $\begin{array}{c}\text { Optimized } \\
\text { value }\end{array}$ & $\begin{array}{c}\text { Range } \\
\text { investigated }\end{array}$ \\
\hline $\begin{array}{c}\text { Mobile phase } \\
\text { Buffer: } \mathrm{CH}_{3} \mathrm{CN}(\mathrm{v} / \mathrm{v})\end{array}$ & $70: 30$ & $65: 35-75: 25$ \\
\hline $\mathrm{pH}$ of buffer sol. & 4 & $4.1-3.9$ \\
\hline Flow rate $(\mathrm{ml} / \mathrm{min})$ & 1.5 & $1.6-1.4$ \\
\hline$\lambda(\mathrm{nm})$ & 298 & $299-297$ \\
\hline
\end{tabular}

The experimental domain of selected variables is reported in Table (3). The ranges examined were small deviations from the method settings and the considered response was the peak area. 
Table 3: Experimental matrix for robustness testing.

\begin{tabular}{||c|c|c|c|c|c||}
\hline $\begin{array}{c}\text { Exp. } \\
\text { no. }\end{array}$ & $\begin{array}{c}\text { Run } \\
\text { order }\end{array}$ & b1 & b2 & b3 & b4 \\
\hline 1 & 5 & 1 & 1 & 1 & -1 \\
\hline 2 & 6 & -1 & 1 & 1 & 1 \\
\hline 3 & 8 & -1 & -1 & 1 & 1 \\
\hline 4 & 12 & 1 & -1 & -1 & 1 \\
\hline 5 & 1 & -1 & 1 & -1 & -1 \\
\hline 6 & 3 & 1 & -1 & 1 & -1 \\
\hline 7 & 11 & 1 & 1 & -1 & 1 \\
\hline 8 & 9 & -1 & -1 & -1 & -1 \\
\hline 9 & 4 & 0 & 0 & 0 & 0 \\
\hline 10 & 2 & 0 & 0 & 0 & 0 \\
\hline 11 & 7 & 0 & 0 & 0 & 0 \\
\hline 12 & 10 & 0 & 0 & 0 & 0 \\
\hline
\end{tabular}

$\mathrm{b}_{1}: \%$ organic modification

where $(0)$ is the same optimum value

$\mathrm{b}_{2}: \mathrm{pH}$

$\mathrm{b}_{3}: \lambda, \mathrm{nm}$

b4: flow rate, $\min$

(-1) optimum value, -1

(+1) optimum value, +1

A linear relationship between y (area under the peak) and $\mathrm{x}$ (conc) (Eq. (1)) with four variables was postulated and plackett-Burman design was chosen for the coefficients evaluation. $^{10}$

$y=b_{0}+b_{1} x_{1}+b_{2} x_{2}+b_{3} x_{3}+b_{4} x_{4}$

where $b_{1}$ is (organic modifier percentage)

$\mathrm{b}_{2}=\mathrm{pH}$

$\mathrm{b}_{3}=\lambda$

$\mathrm{b}_{4}=$ flow rate

To test the model linearity, four experiments at the optimized conditions, corresponding to the center of experimental domain, were carried out. The experimental matrix is reported in Table 4.

The regression model assumed was found not significant by means of analysis of variance but the graphic analysis of effects (Fig. 1) pointed out that the factor flow rate caused statistically significant variation of the response. Graphic analysis of effects is a tool of experimental design in which the numerical values of the effects are displayed. This analysis requires the construction of a bar graph in which the length of each bar is proportional to the absolute affect value. The effects that exceed the reference lines, corresponding to the $95 \%$ confidence interval, are those significant for the response. ${ }^{11-13}$ In this case the variation in flow rate was significant and then exerts critical effects on the response. Concluding the method can be considered robust but a precautionary statement about flow rates have to be included in the procedure.

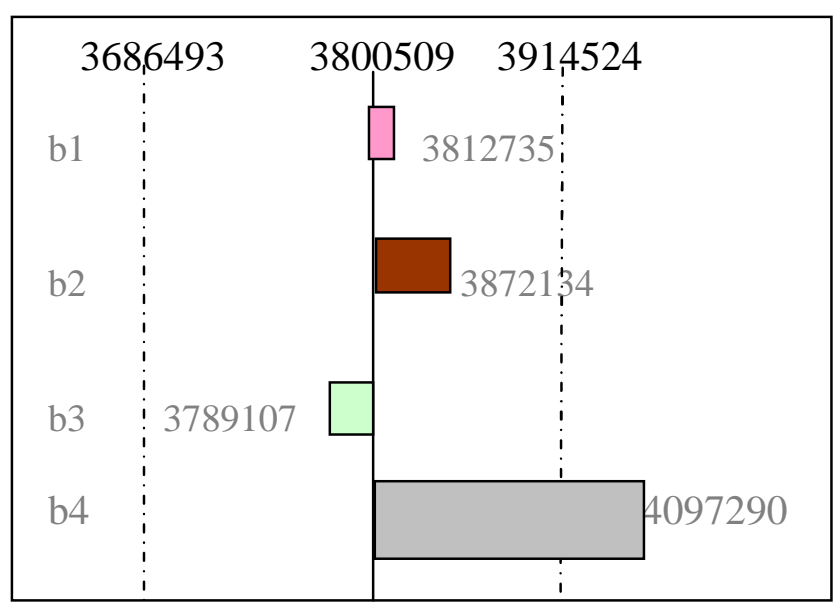

Fig. 1: Graphic analysis of effects for the response peak area during robustness test.

\section{Intermediate precision}

The intermediate precision is a measure of precision between repeatability and reproducibility. It is obtained when the assay is performed by multiple analysts, using multiple instruments, on multiple days, in one laboratory. Because these parameters influence the response together, it is advisable to study these effects simultaneously. In this case the factors considered were the analyst (analyst 1 and analyst 2), the instrument (HPLC 1 and HPLC 2) and the day (day 1 and day 2). A linear model $\left(y=b_{0}+b_{1} x_{1}+b_{2} x_{2}+b_{3} x_{3}+b_{4} x_{4}\right)$ was assumed and a full factorial design $2^{3}$ was employed to estimate the model coefficients. ${ }^{14}$ The considered response was the Ketotifen Fumarate found amount. Each experiment was repeated three times in order to evaluate the experimental error.

The analyses were carried out in a randomized order according to the experimental plan reported in Table 4. The level of Ketotifen Fumarate was $\sim 0.818 \mathrm{mg} / \mathrm{ml}$. the regression model was found not significant, thus indicating that no factor considered influence the response. Besides the RSD found 
in this condition $(0.49 \%, \mathrm{n}=24)$ was acceptable with respect to RSD $(0.52 \%, \mathrm{n}=12)$ found in the repeatability study.

Table 4: Experimental plan to study intermediate precision and obtained responses.

\begin{tabular}{|c|c|c|c|c|}
\hline Trials & Analyst & Day & Instrument & $\begin{array}{c}\text { Response } \\
(\%)\end{array}$ \\
\hline 1 & 1 & 1 & HPLC1 & 101.21 \\
\hline 2 & 1 & 1 & HPLC1 & 101.11 \\
\hline 3 & 1 & 1 & HPLC1 & 100.79 \\
\hline \multicolumn{5}{|c|}{$\overline{\mathrm{X}}=101.36$} \\
\hline 4 & 1 & 2 & HPLC1 & 100.58 \\
\hline 5 & 1 & 2 & HPLC1 & 100.86 \\
\hline 6 & 1 & 2 & HPLC1 & 100.50 \\
\hline \multicolumn{5}{|c|}{$=100.65 \bar{X}$} \\
\hline 7 & 2 & 1 & HPLC1 & 100.99 \\
\hline 8 & 2 & 1 & HPLC1 & 100.73 \\
\hline 9 & 2 & 1 & HPLC1 & 101.14 \\
\hline \multicolumn{5}{|c|}{$\overline{\mathrm{X}}=100.95$} \\
\hline 10 & 2 & 2 & HPLC1 & 100.84 \\
\hline 11 & 2 & 2 & HPLC1 & 100.99 \\
\hline 12 & 2 & 2 & HPLC1 & 100.50 \\
\hline \multicolumn{5}{|c|}{$\overline{\mathrm{X}}=100.77$} \\
\hline 13 & 1 & 1 & HPLC2 & 99.98 \\
\hline 14 & 1 & 1 & HPLC2 & 99.60 \\
\hline 15 & 1 & 1 & HPLC2 & 100.53 \\
\hline \multicolumn{5}{|c|}{$\overline{\mathrm{X}}=100.03$} \\
\hline 16 & 1 & 2 & HPLC2 & 100.32 \\
\hline 17 & 1 & 2 & HPLC2 & 99.94 \\
\hline 18 & 1 & 2 & HPLC2 & 99.83 \\
\hline \multicolumn{5}{|c|}{$\overline{\mathrm{X}}=100.03$} \\
\hline 19 & 2 & 1 & HPLC2 & 100.78 \\
\hline 20 & 2 & 1 & HPLC2 & 100.97 \\
\hline 21 & 2 & 1 & HPLC2 & 101.20 \\
\hline \multicolumn{5}{|c|}{$\bar{X}=100.98$} \\
\hline 22 & 2 & 2 & HPLC2 & 99.51 \\
\hline 23 & 2 & 2 & HPLC2 & 100.44 \\
\hline 24 & 2 & 2 & HPLC2 & 100.35 \\
\hline \multicolumn{5}{|c|}{$\overline{\mathrm{X}}=100.1$} \\
\hline
\end{tabular}

\section{Application on pharmaceutical dosage forms}

The Developed method was applied also for the analysis of Ketonil tablets for the determination of their assay percent (Recovery) in the following manner:

Sample name: Ketonil $1 \mathrm{mg}$ tablets (Batch Number 282).
Manufacturer: RAM PHARMA, AmmanJordan.

Dose: Each 150 mg Ketonil Tablets contain 1 mg Ketotifen base.

Mean for assay percent was $99.6 \%$ and RSD\% was $0.2 \%$.

\section{Conclusion}

The developed method show high specifity and selectivity for ketotifen in the tablet matrix. It was applied also for the analysis of other ketotifen dosage forms.

\section{REFERENCES}

1- A. Williams David and L. Lemke Thomas, in Foye's "Principles of Medicinal Chemistry", Fifth Ed. (2002).

2- DENG Yang-Mei2, XIE Qiang-Min, CHEN Ji-Qiang, BIAN Ru-Lian, Acta Pharmacol. Sin, 24, 1039 (2003).

3- W. Nemrod. D. Mathieu. J. Nony. R. Phan-Tan-Luu, LPRAI SARL, Marseilles, F-13331. France. (software)

4- Topic Q2B, Validation of Analytical Methods: Methodology: The Third International Conference on Harmonization of Technical J. Pharm. Biomed. Anal., 15, 1585 (1997). Requirements for Registration of Pharmaceuticals for Human Use. 1CH.3, Yokohama, Japan. 29 November - I December (1995).

5- S. Futlanrtto, S. Pinzauti, P. Gratteri., E. La Porta and G. Calzeroni, J. Pharm. Biomed. Anal., 15, 1585 (1997).

6- K. D. Altria, B. J. Clark, S. D. Filbey, M. A. Kelly, D. R. Rudd, Electrophoresis 16, 2143 (1995).

7- Y. Van der Heyden, D. L. Massari, in: M.M.W.B. Hendriks. J. H. de Boer. A. K. Smilde (Ed.). "Robustness of Analytical Chemical Methods and Pharmaceutical Technological Products". Elsevier. Amsterdam, 1996, p. 33.

8- S. Furlanetto, C. Tognini, R. Carpenedo, E. La Porta and S. Pinzauti, J. Pharm. Biomed. Anal., 18, 67 (1998).

9- S. Furlanetto, S. Pinzauti. E. La Porla, A. Chiarugi, P. Mura and S. Orlandini, ibid., 17, 1015 (1998).

10- R. L. Plackett and J. P. Burmann., Biometrika, 305 (1943). 
11- R. V. Lenth, Technometrics, 3, 469 (1989).

12- G. A. Lewis, D. Mathieu. R. Phan-TanLuu. "Pharmaceutical Experimental Design". Marcel Dekker, New York (1999).
13- R. Ficarra, P. Ficarra, S. Tommasini, S. Melardi, M. L. Calabro, S. Furlanetto and M. Semreen, J. Pharm. Biomed. Anal., 23, 169 (2000).

14- A. Abdul Halim, A. Naddaf and M. Semreen, International Journal of Chemistry India, Ref.No.IST/IJC/V. 14(4)/2004/627 Accepted for publication. 